OPEN ACCESS

Edited by:

Reyes Llopis-Garcia, Columbia University, United States

Reviewed by: Dusan Stamenkovic, University of Niš, Serbia

*Correspondence: Luna Filipović

I.filipovic@uea.ac.uk

Specialty section: This article was submitted to

Language Sciences,

a section of the journal Frontiers in Communication

Received: 25 November 2021 Accepted: 12 January 2022

Published: 04 March 2022

Citation:

Filipović L (2022) A Multi-Factor Approach to the Study of $L 2$ Acquisition of Motion Verbs and Motion Constructions: Integration of Typological, Psycholinguistic and Sociolinguistic Aspects.

Front. Commun. 7:822517. doi: 10.3389/fcomm.2022.822517

\section{A Multi-Factor Approach to the Study of L2 Acquisition of Motion Verbs and Motion Constructions: Integration of Typological, Psycholinguistic and Sociolinguistic Aspects}

\author{
Luna Filipović * \\ School of Politics, Philosophy, Language and Communication Studies, University of East Anglia, Norwich, United Kingdom
}

Talking about motion events in L2 is done in different ways by different speakers on different occasions. This is due to multiple factors, typological, psycholinguistic and sociolinguistic, which interact and play a role in $L 2$ acquisition and use. These factors can sometimes lead the same types of $\mathrm{L} 2$ speakers to produce very different outputs and sometimes very different $L 2$ speakers to produce the same or similar outputs. In order to capture this diversity of outcomes the CASP (Complex Adaptive System Principles) for Bilingualism model was proposed and we illustrate how this model helps us formulate predictions about motion event verbalizations, set up experiments and account for results in a holistic manner, taking into consideration the relevant multiple factors. Furthermore, a lot of effort in the field has gone into contrasting monolingual and bilingual populations while more knowledge is needed about how different bilingual populations compare. These different bilinguals, including $L 2$ learners, need to be tested under different conditions in which they use their languages (e.g., when only one or both is actively used with vs. without the possibility to code-switch) in order to understand the variability of $L 2$ verbal behaviours and the underlying factors at play under different circumstances of acquisition and use. This perspective paper provides both theoretical and empirical indications how this can be done, with the key message that future research into L2 acquisition (and bilingualism in general) must be based on a multi-factor approach.

Keywords: CASP for Bilingualism, cause, intentionality, manner, multi-factor model, English, Spanish

\section{INTRODUCTION}

Motion events are expressed differently in different languages due to different systemic restrictions or usage preferences. For example, in some languages the use of manner verbs is restricted due to underlying semantic or morphosyntactic rules (as in Romance or Slavic families) while some other languages have no such restrictions but still exhibit some strong usage preferences (e.g., a preference for manner verbs over path verbs in motion expressions, as in the Germanic languages; see Filipović and Ibarretxe-Antuñano, 2015, for a recent overview). These differences formed the basis for a semantic typology of languages (Talmy, 1985; Slobin, 1996; Slobin, 1997; Talmy, 2000; Slobin, 2003; 
Slobin, 2006), which is essentially based on where the defining component of a motion event, that of $\mathrm{Path}^{1}$, is given, i.e., in the verb or out of the verb, which consequently determines the outlook of the whole motion event expression.

These typological differences lead to differences in thinkingfor-speaking, i.e., on-line conceptualization that takes place when speakers verbalize events (Slobin, 1987; Slobin, 1996; Slobin, 1997; Slobin, 2003; Slobin, 2006). When learning a second language (L2) with a different motion lexicalization pattern from that in the first language (L1), an L2 learner may need to re-think for speaking (Ellis and Cadierno, 2009) and shift the linguistic (and also possibly attentional and conceptual) focus from the L1 categories onto the event components, meanings and forms required by the L2 pattern. However, it is not possible to completely switch off the first language, even when the bilingual speaker has a high level of control through balanced early or fluent late (L2) bilingualism (De Groot, 2011). Crucially, even if bilinguals are able to keep their L1 (stronger language) in check to a great degree when speaking their L2 (weaker language) they are likely to do so more successfully on some occasions and less so on others, and their outputs will be very different as a result. Multiple factors condition bilingual language production, though the literature on L2 acquisition, and bilingualism more generally, has shied away from attempts at a multi-factor approach in investigations, both theoretical and empirical. In particular, the psycholinguistic and sociolinguistic factors relevant for bilingualism have been addressed in two completely different spheres of scholarly endeavour, rarely connecting to each other, with the two communities of researchers having separate research agendas, conferences and publication outlets, with neither side seemingly aware of the relevant findings produced by the other. A unifying platform is obviously needed, since bilingualism affects, and is affected by, both the mind and the society (see Jarvis and Pavlenko, 2010; Filipović and Hawkins, 2013; Muysken, 2013). In addition, there have been calls in the field of bilingualism research to shift focus from contrasting monolinguals and bilinguals to comparisons among different bilingual populations, with more considerations given to relevant individual differences within these populations as well as differences in the circumstances of their language use (see Vaid and Meuter, 2017; Bassetti and Filipović, 2021).

This paper is a call to embrace a multi-factor approach in L2 acquisition research, and bilingualism research more generally. Such an approach would need to inform all stages of scientific investigation, from the formulations of research questions and study design, to the selection of different types of bilingual participants and inclusion of different experimental conditions. In the following Section 2 I illustrate how this may be done using data from multiple experiments on L2 production of both

${ }^{1}$ Path is the defining component of a motion event according to Talmy (1985) because it has to be mentioned in all motion expressions. Without Path there is no motion (though there may be movement) since motion is defined as change of location. agentive and caused motion expressions by different EnglishSpanish bilinguals.

\section{CASP FOR BILINGUALISM MODEL}

The central argument in this perspective paper is that, in order to provide a platform for a holistic outlook on bilingual acquisition and use of motion verbs and constructions, we would need to integrate multiple factors that affect acquisition and language use within and across bilingual minds. The CASP (Complex Adaptive System Principles) model was proposed to this end by Filipović and Hawkins (2013), initially just in relation to second language acquisition (CASP for SLA), and it was later extended to include all types of bilingual acquisition and use (CASP for Bilingualism; Filipović and Hawkins, 2019). It is based on insights from extensive learner corpus and experimental data (ibid).

The core theoretical assumption of the CASP for Bilingualism model is the understanding of language as a complex adaptive system (in the sense of Gell-Mann, 1992), within which multiple factors interact to produce a range of observable outcomes. Bilingual language systems need to be understood in the same way, and similar views have been voiced in the past. Some studies in second language acquisition have recognised the need for addressing multiple interacting factors in attempts to understand, and account for, different kinds of bilingual language acquisition (see, for example, Ellis, 1998; O'Grady, 2005; Mellow, 2008; O'Grady, 2008; Ellis and Larsen-Freeman, 2009). These studies differ in the number and nature of the principles they propose, in their precise formulation, in the predictions they make for interlanguage data, and in the range of data on which they have actually been tested. The empirical support has so far been very encouraging but still limited. We need to ensure a more significant uptake of this kind of approach and include significantly larger and diverse data sets as well as many more language combinations spoken by different bilinguals in different types of interactions, monolingual and bilingual.

The CASP for Bilingualism model has five general principles, four of which apply to all language processing and acquisition situations, while the fifth is bilingual-specific (i.e., it requires two different language systems). These principles are: Minimize Learning Effort ("acquire simple items and rules first"), Minimize Processing Effort ("use simple items more often"), Maximize Expressive Power ("learn more complex items and rules so you can express all the meanings you wish to express, in the L1 and in the L2 as well if bilingual"), Maximize Efficiency in Communication ("use complex over simple items only when context or the specific communicative goal requires you to do so; e.g., in order to pick out a referent in conversation sooner and more precisely you may say "the professor we mentioned yesterday said that' as opposed to the grammatically simpler and shorter 'he said that"), and Maximize Common Ground ("use what works in both languages whenever you can, especially when both languages are active in the same communicative situation"). The psycholinguistic incentive to produce "shared patterns" that lies behind the Maximize Common Ground principle can be related to what is known as "alignment" or "accommodation" 
in interaction (i.e., the tendency of speakers to use the same patterns as their interlocutors), which has been studied mainly in monolingual contexts and which is done unconsciously/ automatically (though the extent to which it is carried out can be socially-mediated; see Weatherholtz et al., 2014 for details). The difference is, however, that in the present context we talk about alignment and maximizing the common ground between two linguistic systems within one bilingual mind, not alignment between minds, i.e., between two interlocutors (though the alignment/accommodation between minds can occur as well and independently since this is a general interactional phenomenon).

The principle of Maximize Common Ground is the same underlying process that encompasses what was commonly known as 'transfer' (Odlin, 1989) or 'cross-linguistic influence' (Jarvis and Pavlenko, 2010), and includes both adding (complexifying) and omitting (simplifying) information, which takes place in order to align the two systems. ${ }^{2}$ Multiple examples from both the psycholinguistic and sociolinguistic literature illustrate which outcome is more likely and when (see Filipović, 2019, for details). These five general principles sometimes collaborate and sometimes compete, depending on the internal and external factors operating in any given communicative situation. As outlined in Filipović (2019), internal (variability) factors comprise age of acquisition, proficiency and dominance, which may be affected by numerous conditions (e.g., languages spoken at home, the language of primary school education, the amount of exposure to second languages, the specific language testing context; see also Bylund and Athanasopoulos, 2014; SilvaCorvalán and Treffers-Daller, 2015). External factors are driven by the inherently adjustable nature of bilingual linguistic behaviour, modulated by proficiency, which depends on the interlocutor types involved (i.e., who bilingual speakers are talking to; see Filipović and Hawkins, 2013, Filipović and Hawkins, 2019; Filipović, 2019) or the type of communicative situation a bilingual is involved in (e.g., formal vs. informal; see Dewaele, 2001). For instance, the same bilingual speaker will produce different outputs when talking to another bilingual speaker of the same two languages compared to when he or she communicates with a monolingual speaker of one of the two languages [see also discussion in Muysken (2013: 714) on different factors that impact outputs in language contact situations]. Green and Abutalebi (2013: 515-516) argue that it is the control processes that adapt to the different demands of different communicative contexts of single language, dual language or dense code switching. They define the single language context as the one in which each language is spoken in different environments (e.g., home vs. work). Dual language contexts involve the use of both languages with different speakers, possibly within a single communicative situation but not within an utterance, and dense code-switching occurs when both languages are used within a single utterance, e.g., when

\footnotetext{
${ }^{2}$ See Filipović (2019) for reasons why the principle of Maximize Common Ground captures more precisely the nature of the processing mechanisms behind the outputs we get in bilingual production compared to some earlier concepts such as positive vs. negative transfer.
}

speaking to another bilingual with the same language combination (Green and Abutalebi, 2013: 518; see also Grosjean, 2001 for a related concept of language mode).

The research into L2 acquisition of motion verbs and constructions needs to consider of these aspects, typological, internal and external, as well as general mechanisms of bilingual acquisition and processing as proposed within the CASP for Bilingualism model. I illustrate next what kind of insights this type of approach can enable us to gain.

\section{L2 ACQUISITION AND USE OF MOTION VERBS AND CONSTRUCTIONS}

English and Spanish are typologically different when it comes to which components of a motion event are expressed where and how often. We will zoom in here on two event components, Manner and Cause.

In English, the manner of motion is preferably expressed in the verb (as in 'limp out'), while in Spanish the combination of manner verbs + path particles is blocked (see e.g., Slobin, 1996; Filipović, 2008). This is due to a semantic restriction in Spanish prepositions-they only express location of motion not direction or change of location. Instead, the grammatically permitted construction in Spanish will be 'salir cojeando' = 'exit limping,' which is also possible but dispreferred in English. Consequently, information about the Manner component is often absent in verbalizations of motion events in Spanish and omitted in translations from other manner-rich languages like English (Slobin, 1996; Slobin, 2003; Slobin, 2006).

When it comes to expressing caused motion events, Spanish has a clear distinction between intentional and non-intentional causation, which is drawn using different verbs and/or constructions for the two event types respectively [ $X$ lanzó $Y$ ('X threw Y') vs. se le cayó $Y$ a X ('to Y it happened that $\mathrm{X}$ fell')]. Such a clear lexicalized distinction is not present in English grammar or usage and even though it can be drawn periphrastically (e.g., by introducing adverbials 'accidentally' vs. 'on purpose'), it is not habitually done by English speakers (see Filipović, 2007; Filipović, 2018; Filipović, 2019 for details).

Numerous studies have reported the effect of typological differences on the process of acquisition of motion expressions in both monolingual and bilingual contexts. However, the reported results are often contradictory. Sometimes it is the stronger language, L1 that affects the outputs in L2, sometimes is the other way around, and sometimes there is no effect (see Pavlenko, 2014, for an extensive and detailed overview of all these outputs). There is often the issue of task type (e.g., the kind of visual stimuli used-still images vs. videos; the kind of responses required-including/impeding verbalization or not, etc.; see Filipović (2019), for a detailed discussion). We can put all these task-related differences aside for a moment, for the sake of uniformity of the comparison at hand, and just look at the differences in the reported verbalization of motion events in two different experiments as a way of illustrating the differences in L2 outputs and of explaining how we can account for them using the CASP for Bilingualism model. 
TABLE 1 | Multiple factors in bilingualism.

\begin{tabular}{|c|c|c|}
\hline A. Speaker type & B. Interlocutor type & C. Language property type \\
\hline $\begin{array}{l}\text { i) Balanced } \\
\text { bilinguals }\end{array}$ & $\begin{array}{l}\text { i) One or more bilinguals in the same two languages (dual language } \\
\text { condition-code-switching potential) }\end{array}$ & $\begin{array}{l}\text { i) Partial overlap (present in both but with different grammatical/usage } \\
\text { rules; e.g., adjective ordering) }\end{array}$ \\
\hline ii) L2 Learners & $\begin{array}{l}\text { ii) Two or more monolinguals, at least one in each language (dual language } \\
\text { condition-no code switching) }\end{array}$ & ii) Presence vs absence of categories (e.g., evidentials) \\
\hline $\begin{array}{l}\text { iii) Heritage } \\
\text { speakers }\end{array}$ & $\begin{array}{l}\text { iii) One or more monolinguals in only one of the two languages (single } \\
\text { language condition) }\end{array}$ & $\begin{array}{l}\text { iii) Incompatibility (e.g., either-or choice, such as basic word order SVO } \\
\text { vs SOV) }\end{array}$ \\
\hline
\end{tabular}

So, what happens then with regard to the expression of Manner and Cause when speakers of English and Spanish are learning L2 Spanish and L2 English respectively? Do they rethink for speaking in their L2, how, when, and how consistently? We can answer these questions only if we test the same bilinguals under different circumstances and also different bilinguals under the same circumstances, bearing in mind that the performances will be modulated by the nature of the specific typological features in question (see the end of this section for more discussion and also for the summary of relevant interacting factors in Table 1).

If we look at the reported experimental data (Filipović, 2011; Filipović, 2018; Filipović, 2020; Filipović, 2021), it seems that, even though the L2 learner populations in the relevant experimental work were matched as closely as possible with respect to their acquisition journeys (in terms of age of acquisition, proficiency, type of L2 instruction, length of stay in L2 country, etc.), and even though they were tested under the same experimental condition (dual language activation; Green and Abutalebi, 2013) they demonstrated apparently different within-group and between-group linguistic behaviours with regard to the two event components in question. In agentive motion, with respect to the Manner of motion, on most occasions the L1 English/L2 Spanish speaker group seems to have done the re-thinking-for speaking (Ellis and Cadierno, 2009) while the other learner group, the L1 Spanish/L2 English speakers, did not. L1 English/L2 Spanish speakers and their L1 Spanish/L2 English peers both rely on the same pattern, namely that of Spanish in their respective L2s (thus providing no or limited mention of Manner):

1a) Una mujer salió con pasos lentos y atraversó el jardín.

A woman exit-PST.3SG with steps slow and cross-PST.3SG the garden.

1b) A woman went out of the building slowly and turned right.

L1 English/L2 Spanish learners may occasionally use their L1 pattern in their L2, which is grammatically incorrect (and marked * in 2a) below), probably due to incomplete L2 acquisition. On the other hand, L1 Spanish/L2 English speakers do not have such potential for error because their L1 pattern is acceptable in their L2, as illustrated in the following L2 verbalizations, respectively:

2a) *El hombre saltó y corrió a través della calle y en el jardín.
A man jump-PST.3SG and run-PST.3SG across-the street and in the garden.

2b) A man went out of the garden, crossed the street and entered another garden.

By contrast, with regard to the event component of Cause, both learner populations apparently use the same strategy of sticking to their respective L1 lexicalization habits when using the L2. The L1 English/L2 Spanish speakers again adhere to their L1 English pattern of not specifying intentionality in causation. This is very different to the L1 Spanish/L2 English speakers, who now use their L1 Spanish pattern in their L2 English thus providing precise detail about Cause in their L2 English verbalizations, even though they do not have to. This contrast is illustrated in the following examples, from L2 English (3a) and 4a)) and L2 Spanish 3b) and $4 \mathrm{~b}))$ :

3a) The woman accidentally dropped a pen while writing.

3b) Su bolido cae.

Her pen falls.

4a) The woman pushed the bottle by accident and it fell off the table.

4b) La mujer empujó la botella de la mesa.

The woman pushed the bottle off the table.

CASP for Bilingualism can help us explain the apparent differences in the two observed L2 acquisition patterns and outputs. According to the principle of Maximize Common Ground the two bilingual groups with different L1s are both using a grammatically licensed pattern in their L2 that can work in both their languages, but they are doing it in different ways for different typological dimensions and due to the different stronger (L1) language. ${ }^{3}$ In agentive motion, the English pattern of manner verb + path preposition is not permissible in Spanish but the Spanish pattern of path verb + optional manner adjunct is permissible in English, so it is by and large the Spanish pattern that is used in both L2s. The English learners of L2 Spanish have an obvious incentive to re-think for speaking because they could not just go ahead and use their L1 pattern

${ }^{3}$ Comparable L2 (and general bilingual) preference for syntactic patterns that work in both languages has been noted before in studies of both agentive motion (Hohenstein et al., 2006) and caused motion (Engemann et al., 2012), as well as in other domains such as syntactic attachment (see Fernandez, 2002; Dussias, 2003; Dussias and Sagarra, 2007; see also Filipović, 2014, for overview). 
in their L2, it would be ungrammatical, and they are of an advanced enough level to know this. ${ }^{4}$ In contrast, the L1 Spanish learners of L2 English have little incentive to restructure their agentive motion expressions to fit the L2 English pattern because they can get by using their L1 Spanish pattern in L2 English because it is grammatical albeit dispreferred. Thus, we end up with the same, shared Spanish pattern in both L2 Spanish and L2 English.

By contrast, when it comes to expressing caused motion, the principle of Maximize Common Ground leads the two learner groups to resort to different strategies, driven by the internal factor of stronger (L1) language proficiency. Namely L1 English speakers can get by with not expressing Cause and using structures neutral to intentionality (as in 'the bottle fell'), which are still grammatical though dispreferred in Spanish, but which leads to an important event detail being unexpressed. By contrast, L1 Spanish/L2 English speakers habitually add information about intentionality in L2 English and thus maximize common ground between their L1 (which consistently focuses their attention on this component) and their L2 (in which this information can be added optionally). This outcome is also supported by another general principle, Maximize Expressive Power (i.e., ability to convey all meanings from L1 in the L2), which gives the incentive to L1 Spanish speakers to express all the relevant L1 meanings in their L2 English. This is the incentive that the L1 English learners do not have on this occasion since their L1 English does not draw such meanings distinctions, and for L1 English/L2 Spanish speakers this principle is also further trumped by the Minimize Learning Effort and Minimize Processing Effort principles.

We have to reiterate that the Maximize Common Ground principle can lead to both omission of information in the two languages or to additions in both, and more so when both languages are contemporaneously active. Which one, addition or omission, will be the case depends on the typological outlook (e.g., what each language has or does not have) and also how easy it is to restructure the expression in a specific case. For example, L2 learners (and also balanced bilinguals; see Filipović, 2011) omit or reduce a lot of Manner detail in verbalizations of motion events because it is difficult to insert this detail into the (shared) Spanish pattern (see Filipović, 2021). However, they may add information for some other event component (e.g., as we saw in the case of Cause) if it is easier to insert it into one of the two languages that does not have it (periphrastically, as in the examples 3a) and 4a); see Filipović, 2018; Filipović, 2020, for details) and if this information is strongly favoured and habitually given in the stronger (L1) language.

It is also crucial to observe that examination of $\mathrm{L} 2$ learners in the studies considered here happened under the dual activation condition-all L2 learners had both languages active in the experiment because the experimenter was using the speakers'

${ }^{4}$ However, early L1 English/L2 Spanish speakers do indeed produce ungrammatical L1 English patterns in L2 Spanish because they have not "figured out" how to Maximize Common Ground properly (Larrañaga et al., 2012).
L1 for instruction and communication throughout, after presentation of each item, while asking the participants to verbalize only in their L2. Under the single language condition, especially if that language is the stronger one of the two (i.e., L1), we can expect different outcomes, as previous research has reported in a variety of experimental set ups (see again Pavlenko, 2014). Balanced bilinguals can come closer to monolingual norms in both their languages under single language conditions while L2 learners could be expected to achieve this in their L1 but not in their L2 (unless they are almost equally proficient in both L1 and L2). All these assumptions, including different bilinguals and different conditions of activation, await further testing that would involve typologically different languages and different event components, especially the lesser studied ones (such as Deixis or Cause; see Andria and Hijazo-Gascón, 2021). The table above summarizes the different factors whose combinations and interactions need to be addressed (see also Filipović, 2019: 74 for more details), preferably using the same task in experimental elicitation as well as when studying authentic interaction data (for specific multi-factor-driven predictions and specific methodological set-ups see Filipović, 2019: 112). For example, the same bilingual group of speakers (e.g., balanced bilingual; see Table 1, under A.i)) should be tested under different conditions (Table 1, B.i-B.iii) as well as for different types of linguistic properties (Table 1, C. i-C.iii). In addition, different bilingual groups (Table 1, A.i-A.iii) need to be tested contrastively under the same conditions (e.g., Table 1, B.ii) and for the same linguistic property (e.g., Table 1, C.iii). Only then will we be able to understand fully when and why the same bilinguals exhibit different linguistic behaviours under different conditions as well as why different bilingual populations may produce the same outputs on some occasions but not on others.

\section{CONCLUSION}

In this paper we have argued that multiple factors in the acquisition of motion expressions in different L2s need to be captured holistically, taking into account a) different typological contrasts in verbalization of different cognitive domains (focusing on what is obligatory vs. optional or habitually preferred to express), b) internal factors (that modulate speaker profiles, including proficiency, dominance, etc.) and c) external factors (that modulate communicative situation profiles, including interlocutor type, formality setting, etc.), and d) underlying general principles of bilingual language acquisition and processing, as proposed in the CASP for Bilingualism model. It is crucial to identify the relevant subset of factors from the multi-factor model that will drive the predictions for the specific case under investigation and to then assess how these factors work together in that particular case. Sometimes one factor will not interfere with the predictions of another. Sometimes it will. Sometimes multiple factors will co-operate and pull in the same direction, sometimes they will compete. Crucially, we 
also need convergent evidence from different and large datasets, e.g., both corpus and experimental (as exemplified in the work of Filipović and Hawkins, 2013, Filipović and Hawkins, 2019; and Filipović, 2019).

Another important, and still less often trodden path in the present context is the necessary search for understanding whether and how multiple factors in L2 acquisition and use have effects on whether and how often specific details about events (e.g., manner of motion, intentionality of agents, or position of objects) are provided in descriptions and also remembered (see Filipović, 2011; Koster and Cadierno, 2018; Filipović, 2020), as well as what kinds of real-life consequences may follow from such effects for individuals and societies (see Filipović, 2017a, Filipović, 2017b; Hijazo-Gascón, 2019 for details on an Applied Language Typology research programme).

Having multiple factors to consider does not make the overall predictions easy, but it does not make them impossible, as long as we delimit the empirical domain of applicability for each factor

\section{REFERENCES}

Andria, M., and Hijazo-Gascón, A. (2021). "Deictic Motion Verbs in Greek as a Foreign Language by Spanish and Catalan L1 Learners: a Preliminary Approach," in Presentation at the Societas Linguistica Europaea conference (on-line).

Bassetti, B., and Filipović, L. (2021). Researching Language and Cognition in Bilinguals. Int. J. Bilingual. doi:10.1177/13670069211022860

Bylund, E., and Athanasopoulos, P. (2014). Linguistic Relativity in SLA: Towards a New Research Programme. Lang. Learn. 64 (4), 952-985.

De Groot, A. M. B. (2011). Language and Cognition in Bilinguals and Multilinguals: An Introduction. New York, NY: Psychology Press.

Dewaele, J.-M. (2001). “Activation or Inhibition? the Interaction of L1, L2 and L3 on the Language Mode Continuum," in Cross-linguistic Influence in Third Language Acquisition: Psycholinguistic Perspectives. Editors J. Cenoz, B. Hufeisen, and U. Jessner (Clevedon, UK: Multilingual Matters), 69-89. doi:10.21832/9781853595509-006

Dussias, P. E. (2003). Syntactic Ambiguity Resolution in Second Language Learners: Some Effects of Bilinguality on L1 and L2 Processing Strategies. Stud. Second Lang. Acquisition 25, 529-557.

Dussias, P., and Sagarra, N. (2007). The Effect of Exposure on Syntactic Parsing in Spanish- English Bilinguals. Bilingualism: Lang. Cogn. 10 (1), 101-116. doi:10. $1017 /$ s 1366728906002847

Ellis, N. C., and Cadierno, T. (2009). Constructing a Second Language. Arcl 7, 111-139. doi:10.1075/arcl.7.05ell

Ellis, N. C. (1998). Emergentism, Connectionism and Language Learning. Lang. Learn. 48 (4), 631-664. doi:10.1111/0023-8333.00063

Ellis, N. C., and Larsen-Freeman, D. (2009). "Constructing a Second Language: Analyses and Computational Simulations of the Emergence of Linguistic Constructions from Usage," in Language as a Complex Adaptive System. Editors N. C. Ellis and D. Larsen-Freeman (Chichester, UK: WileyBlackwell), 59, 90-125. doi:10.1111/j.1467-9922.2009.00537.x

Engemann, H., Harr, A.-K., and Hickmann, M. (2012). "Caused Motion Events across Languages and Learner Types," in Multilingual Cognition and Language Use: Processing And Typological Perspectives [Human Cognitive Processing Series 44]. Editors L. Filipović and M. Pütz (Amsterdam: Benjamins), 263-288. doi:10.1075/hcp.36.15eng

Fernández, E. M. (2002). "Relative Clause Attachment in Bilinguals and Monolinguals," in Bilingual Sentence Processing. Editors R. R. Heredia and J. Altarriba (Amsterdam: Elsevier), 187-215. doi:10.1016/s0166-4115(02) 80011-5

Filipović, L. (2017a). Applied Language Typology: Applying Typological Insights in Practice. Languages in Contrast 17 (2), 255-278.

Filipović, L. (2017b). "Applying Language Typology: Practical Applications of Research on Typological Contrasts between Languages," in Motion And Space and its expected consequences (see Filipović, 2019, for further details and examples from multiple domains in addition to that of motion events). In any case, we have no choice. Any adequate model of $L 2$ acquisition, and bilingualism more generally, must be a multi-factor one.

\section{DATA AVAILABILITY STATEMENT}

The original contributions presented in the study are included in the article and further inquiries can be directed to the corresponding author.

\section{AUTHOR CONTRIBUTIONS}

The author confirms being the sole contributor of this work and has approved it for publication.

across Languages and Applications [Human Cognitive Processing Series 59]. Editor I. Ibarretxe-Antuñano (Amsterdam: John Benjamins), 399-418.

Filipović, L. (2020). Bilingual Memory Advantage: Bilinguals Use a Common Linguistic Pattern as an Aid to Recall Memory. Int. J. Bilingualism 24 (3), 542-555.

Filipović, L. (2019). Bilingualism in Action: Theory and Practice. Cambridge: Cambridge University Press.

Filipović, L. (2014). "Efficiency of the Bilingual Mind: Clues from Processing, Memory and Second Language Acquisition Studies," in Multilingual Cognition and Language Use: Processing And Typological Perspectives [Human Cognitive Processing Series 44]. Editors L. Filipović and M. Pütz (Amsterdam: John Benjamins), 205-227.

Filipović, L. (2021). First Language versus Second Language Effect on Memory for Motion Events: The Role of Language Type and Proficiency. Int. J. Bilingualism, 136700692110228. doi:10.1177/13670069211022863

Filipović, L., and Hawkins, J. A. (2013). Multiple Factors in Second Language Acquisition: The CASP Model. Linguistics 51 (1), 145-176.

Filipović, L., and Hawkins, J. (2019). The Complex Adaptive System Principles Model for Bilingualism: Language Interactions within and across Bilingual Minds. Int. J. Bilingualism 23 (6), 1223-1248.

Filipović, L., and Ibarretxe-Antuñano, I. (2015). "Motion," in Handbook Of Cognitive Linguistics [Handbooks of Linguistics and Communication Science 39]. Editors E. Dąbrowska and D. Dagmar (Berlin: Mouton de Gruyter), 536-545.

Filipović, L. (2011). Speaking and Remembering in One or Two Languages: Bilingual vs. Monolingual Lexicalization and Memory for Motion Events. Int. J. Bilingualism 15, 466-485.

Filipović, L. (2018). Speaking in L2 but Thinking in L1: Language-specific Effects on Memory for Causation Events in English and Spanish. Int. J. Bilingualism 22 (2), 180-198.

Filipović, L. (2007). Talking about Motion: A Crosslinguistic Investigation of Lexicalization Patterns. Amsterdam: John Benjamins.

Filipović, L. (2008). Typology in Action: Applying Insights from Typological Contrasts. Int. J. Appl. Linguistics 18 (1), 42-61.

Green, D. W., and Abutalebi, J. (2013). Language Control in Bilinguals: The Adaptive Control Hypothesis. J. Cogn. Psychol. 25 (5), 515-530. doi:10.1080/ 20445911.2013.796377

Grosjean, F. (2001). “The Bilingual's Language Modes," in One Mind, Two Languages: Bilingual Language Processing. Editor J. Nicol (Oxford, UK: Blackwell), 1-22.

Hijazo-Gascón, A. (2021). Translating Accurately or Sounding Natural. Pragmatics Soc. 10, 73-94. doi:10.1075/bct.118.05hij

Hohenstein, J., Eisenberg, A., and Naigles, L. (2006). Is He Floating across or Crossing Afloat? Cross-Influence of L1 and L2 in Spanish-English Bilingual Adultsfloating across or Crossing Afloat? Cross-Linguistic Influences of L1 and L2 in Spanish-English Bilingual Adults. Bilingualism 9 (3), 249-261. doi:10. $1017 /$ s1366728906002616 
Jarvis, S., and Pavlenko, A. (2010). Crosslinguistic Influence in Language and Cognition. London, UK: Routledge.

Koster, D., and Cadierno, T. (2018). The Effect of Language on Recognition Memory in First Language and Second Language Speakers: The Case of Placement Events. Int. J. Bilingualism 23, 651-669. doi:10.1177/ 1367006918763140

Larrañaga, P., Treffers-Daller, J., Tidball, F., and Gil Ortega, M.-C. (2012). L1 Transfer in the Acquisition of Manner and Path in Spanish by Native Speakers of English. Int. J. Bilingualism 16 (1), 117-138.

Mellow, J. D. (2008). The Emergence of Complex Syntax: A Longitudinal Case Study of the ESL Development of Dependency Resolution. Lingua 118 (4), 499-521.

Muysken, P. (2013). Language Contact Outcomes as the Result of Bilingual Optimisation Strategies. Bilingualism: Lang. Cogn. 16 (4), 709-730.

Odlin, T. (1989). Language Transfer: Cross-Linguistic Influence in Language Learning. Cambridge, United Kingdom: Cambridge University Press.

O’Grady, W. (2005). Syntactic Carpentry: An Emergentist Approach to Syntax. Mahwah, NJ: Lawrence Erlbaum.

O'Grady, W. (2008). The Emergentist Program. Lingua, 447-464.

Pavlenko, A. (2014). The Bilingual Mind and what it Tells Us about Language and Thought. Cambridge, UK: Cambridge University Press.

Silva-Corvalán, C., and Treffers-Daller, J. (2015). Language Dominance in Bilinguals Issues of Measurement and Operationalization. Cambridge, United Kingdom: Cambridge University Press.

Slobin, D. I. (2003). "Language and Thought Online: Cognitive Consequences of Linguistic Relativity," in Language in Mind: Advances in the Study of Language and Thought. Editors D. Gentner and S. Goldin-Meadow (Cambridge, MA: MIT Press), 157-191.

Slobin, D. I. (1997). "Mind, Code and Text," in Essays on Language Function and Language Type. Editors J. Bybee, J. Haiman, and S. Thompson (Amsterdam: John Benjamins), 437-467. doi:10.1075/z.82.24slo

Slobin, D. I. (1987). "Thinking for Speaking," in Proceedings of the Thirteenth Annual Meeting of the Berkeley Linguistic Society, 435-444. doi:10.3765/bls. v13i0.1826
Slobin, D. I. (1996). "Two Ways to Travel: Verbs of Motion in English and Spanish," in Grammatical Constructions: Their Form and Meaning. Editors M. Shibatani and S. A. Thompson (Oxford: Clarendon Press), 195-219.

Slobin, D. I. (2006). "What Makes Manner of Motion Salient? Explorations in Linguistic Typology, Discourse, and Cognition," in Space in Languages: Linguistic Systems and Cognitive Categories. Editors M. Hickmann and S. Robert (Amsterdam: John Benjamins), 59-81.

Talmy, L. (1985). "Lexicalization Patterns: Semantic Structure in Lexical Forms," in Language Typology and Syntactic Description. Editor T. Shopen (Cambridge, UK: Cambridge University Press), 57-149.

Talmy, L. (2000). Toward a Cognitive Semantics (Vols. 1 and 2). Cambridge, MA: MIT Press.

Vaid, J., and Meuter, R. F. I. (2017). "Languages without Borders," in Bilingualism: A Framework for Understanding the Mental Lexicon. Editors M. Libben, M. Goral, and G. Libben (Amsterdam: John Benjamins), 7-26. doi:10.1075/bpa.6.01vai

Weatherholtz, K., Campbell-Kibler, K., and Jaeger, T. F. (2014). Socially-mediated Syntactic Alignment. Lang. Change 26, 387-420. doi:10.1017/s0954394514000155

Conflict of Interest: The author declares that the research was conducted in the absence of any commercial or financial relationships that could be construed as a potential conflict of interest.

Publisher's Note: All claims expressed in this article are solely those of the authors and do not necessarily represent those of their affiliated organizations, or those of the publisher, the editors and the reviewers. Any product that may be evaluated in this article, or claim that may be made by its manufacturer, is not guaranteed or endorsed by the publisher.

Copyright $(\odot) 2022$ Filipović. This is an open-access article distributed under the terms of the Creative Commons Attribution License (CC BY). The use, distribution or reproduction in other forums is permitted, provided the original author $(s)$ and the copyright owner(s) are credited and that the original publication in this journal is cited, in accordance with accepted academic practice. No use, distribution or reproduction is permitted which does not comply with these terms. 